\title{
EL MÉTODO EN POÉTICA 1-6 DE ARISTÓTELES
}

Manuel Berrón

\author{
Universidad Nacional del Litoral
}

\begin{abstract}
Resumen: La premisa que guía nuestra investigación es que Poética es un tratado científico, i. e., que la investigación desarrollada en dicha obra se corresponde con el examen de una téchne. Defendemos que el método utilizado se corresponde con el método general de investigación denominado "salvar las apariencias". Tal método es expuesto con más detalle en otras obras del corpus pero lo presuponemos utilizado en Poética. Si bien el método presupone la recolección de datos, no se limita a eso puesto que el paso ulterior consiste en la caracterización de las diferencias y la exposición de las cuatro causas del fenómeno. De este modo, expondremos por un lado la base fenoménica de Poética y, por otro, sus cuatro causas.
\end{abstract}

Palabras clave: Poética; Aristóteles; tratado científico; phainómena; causas.

\begin{abstract}
Our paper assumes that Poetics is a scientific treatise, i. e., that the developed investigation in Poetics is an examination of a techne. We defend that the method used in Poetics corresponds with the general method so-called "saving the appearances". Aristotle expound such a method in others works of the corpus, but we assume that it is used in Poetics. The method presupposes the recollection of data, buy it does not be limited to this, on the contrary, the next step consist in the characterization of differences and exposition of four causes of phenomena. Thereby, on the one hand we expound Poetics' phenomena and, on the other hand, Poetics' four causes.
\end{abstract}

Keywords: Poetics; Aristotle; scientific treatise; phenomena; causes.

\section{Introducción}

La discusión actual sobre el carácter de la exposición aristotélica en sus tratados científicos sigue siendo materia de polémicas. Por una parte, encontramos la crítica desplegada en la segunda mitad del S. XX a la metodología empleada en aquellos tratados que estableció una presunta incompatibilidad con las prescripciones metodológicas de los Analíticos, tal línea está inspirada por Solmsen (1929) y fue desarrollada con fuerza por Barnes (1969 y 1981) ${ }^{1}$. En este marco, surgió una línea interpretativa derivada

\footnotetext{
1 Barnes defiende dos tesis: por un lado, que no se usa la demostración científica en los tratados de ciencia (1969); por otro y en línea con Solmsen (1929), la tesis de que existiría una protoapodíctica en los Segundos analíticos que habría sido trastocada por el descubrimiento aristotélico del silogismo. Según Barnes, la fascinación por el silogismo de parte de Aristóteles habría obturado el desarrollo de una teoría general de la demostración (1981).
} 
coherentemente de la anterior que buscó revelar cuál fue la metodología realmente utilizada en los diferentes tratados. Entre otros, Owen (1961) desarrolló una interpretación que defiende la tesis de que la herramienta prioritaria habría sido la dialéctica ${ }^{2}$. Estas dos tesis -la discrepancia entre práctica científica y filosofía de la ciencia más el uso de la dialéctica-, que funcionan de modo articulado han comenzado a ser revisadas en la medida en que se estudió la metodología utilizada en el conjunto de obras biológicas del corpus. Las investigaciones de Lennox (1987 y 2001), Gotthelf (1987 y 1997), Devereux y Pellegrin (1990) -en las obras de biología- y de Bolton (1991) y Detel (1997 y 2006) sobre metodología en biología y física suponen una importante revisión de dichas tesis. Además, en una propuesta de lectura diferente, Cleary (1994) defiende una visión que, antes que escindir las diversas variantes metodológicas elaboradas por Aristóteles, a saber: inducción, dialéctica y doxografía, propone una lectura que deja espacio para la integración de estos diversos métodos. Para ello, recurrió a la conocida metodología de "salvar las apariencias" como una interpretación que permite comprender e integrar estas variantes metodológicas ${ }^{3}$. En este marco polémico, pretendemos investigar la metodología que Aristóteles utiliza en la exposición desarrollada en Poética. La premisa que guía nuestra investigación es que Poética es un tratado científico, i. e., que la investigación desarrollada en dicha obra se corresponde con el examen científico propio de una téchne. Si bien existe un consenso sobre el carácter de tratado científico de Poética ${ }^{4}$, no encontramos una lectura que se apropie de este texto para interpretarlo sea en favor de la tesis de la discrepancia o en favor una tesis compatibilista como la que defenderemos. Nuestra perspectiva -como dijimos, de carácter compatibilista- asume que existen una serie de rasgos en la exposición desarrollada a lo largo de Poética que nos permiten aseverar que el examen de

\footnotetext{
2 La tesis de Owen se sostiene en la asunción de que phainómena equivale a éndoxa y que, entonces, toda investigación, incluida aquella que comienza por los phainómena, parte de las premisas de la dialéctica, i. e., los éndoxa. Owen no se encuentra solo en esta línea: le precede una línea "francesa" donde se encuentra Mansion (1945) al que puede sumarse con desarrollos y perspectivas propias Aubenque (1962) y en Alemania a Wieland (1962). Versiones más actuales y elaboradas en línea con la tesis iniciática de Owen se encuentran en Nussbaum (1986) e Irwin (1988).

${ }^{3}$ A decir verdad, la lectura de Cleary defiende que el método de "salvar las apariencias" sirve en el camino del descubrimiento de los principios. De este modo, deja aparte el camino "desde los principios", propio del momento demostrativo dominado por el uso del silogismo. Nosotros consideramos que esta es una carencia de su lectura puesto que consideramos que este camino también forma parte del método, pero en razón del espacio no llegaremos a discutir este punto. Otra posición distinta con la que rivaliza Cleary es la de Irwin (1988), quien argumenta en favor de una división tajante entre dos caminos metodológicos diversos: el empírico y el dialéctico.

${ }^{4}$ Son de esta opinión, entre otros, Husain (HUSAIN, 2002, p.17 ss), Barbero (BARBERO, 2004, p.32 ss), Sinnot (SINNOT, 2006, p.XI-XII), y Suñol (SUÑOL, 2012, p.41-2).
} 
esta técnica puede encuadrarse bajo la metodología general que brinda el esquema de "salvar las apariencias". Con miras a probar nuestra hipótesis (\$1) examinaremos el incipit de Poética para mostrar que allí se alude implícitamente a esta metodología: para explicitar esto conectaremos este pasaje con Partes de los animales A, allí donde, como es bien conocido, Aristóteles establece importante prescripciones empiristas. En ese sentido, uno de nuestros principales objetivos es mostrar cuál es la base empírica o, utilizando el giro que denomina al método, "las apariencias" que deben ser "salvadas". Para alcanzar este objetivo, (\$2) expondremos los phainómena que están en la base de la exposición de Poética. Por otra parte, dado que la explicación última del fenómeno de las artes poéticas depende del hallazgo de las causas para dicho fenómeno, (\$3) mostraremos la presencia de la doctrina de las cuatro causas en Poética 4 a 6. Finalmente, extraeremos algunas conclusiones sobre lo desarrollado y el alcance del método de "salvar las apariencias".

\section{\$1. El incipit de Poética y Partes de los animales A}

No existen en Poética muchas reflexiones metodológicas, sin embargo, en el comienzo de la obra, en el incipit, que reproducimos a continuación, encontramos una serie de detalles sumamente valiosos. ${ }^{5}$ Dice Aristóteles:

\footnotetext{
Hablemos acerca de la poética en sí y de las especies de la misma, respecto de la potencia/efecto que cada una tiene, y de cómo es preciso estructurar las tramas si se tiene la intención de que la poesía resulte bien/bellamente, además de cuántas y cuáles son sus partes, de igual manera también acerca de las otras cosas que son propias de la misma investigación, comenzando conforme a la naturaleza, primero a partir de las cosas primeras ${ }^{6}$ (Poética 1447a8-13, traducción de V. Suñol, [cf. SUÑOL, 2012, p.41-2]).
}

El pasaje presenta un estilo típicamente aristotélico en los distintos aspectos en que se proyecta la investigación, a saber: (i) se afirma que se estudiará la "poética en sî" y "sus especies", (ii) las potencias de la poética, (iii) la composición de la trama y su finalidad propia, (iv) sus partes, (v) y, finalmente, se informa que se avanzará conforme a la naturaleza, i. e., según el procedimiento adecuado para esta investigación: comenzando primero por lo

\footnotetext{
${ }^{5}$ Algunos autores han tratado de quitarle relevancia a este pasaje señalando que puede dudarse de su autenticidad. Tal es la tesis de D. de Montmollin (DE MONTMOLLIN, 1951, p.12ss) quien afirma que la mayor parte del pasaje en cuestión podría tratarse de un mero añadido. Coincidimos con Barbero en su crítica a esta opinión (cf. BARBERO, 2004, p.40-1).

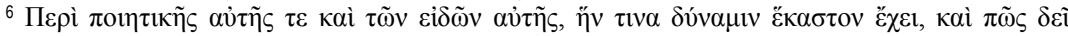

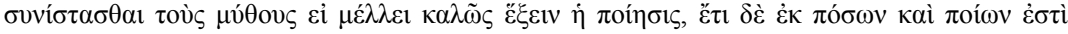

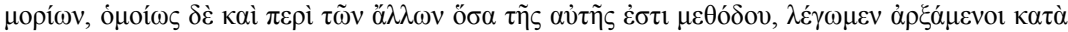

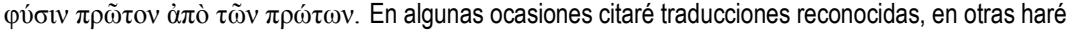
mis propias traducciones, en todos los casos indicaré el proceder.
} 
primero. Para un examen minucioso de los ítems (i-iv), me remito al análisis que hizo del pasaje S. Barbero (2004, p.32-43). Una peculiaridad del incipit es la ausencia de referencia al estudio de las causas de la poética. Es absolutamente habitual que Aristóteles mencione que abordará el estudio de las causas incluso los principios y elementos- del objeto en cuestión pero aquí no lo hace aunque luego, efectivamente, se ocupa de establecer las causas de la poética ${ }^{7}$.

Resulta de un interés especial considerar el último giro del incipit, el ítem (v), puesto que éste conecta con otros pasajes del corpus metodológicamente importantes. El giro, a saber: "comenzando conforme a la naturaleza, primero a partir de las cosas primeras" es relevante puesto que estas palabras no son exclusivas de Poética sino que el giro aparece en otros pasajes $^{8}$. Sin embargo, la expresión aquí no tiene una aclaración concreta y su sentido debe ser buscado por su similitud con otros pasajes del corpus. Existe consenso en que la primera parte del giro, "comenzando conforme a la naturaleza", tiene el sentido técnico de remitir al orden expositivo estándar de Aristóteles. Esto es, a partir de la conocida distinción entre lo primero por sí o por naturaleza y lo primero para nosotros ${ }^{9}$, no se comienza por lo que es primero para nosotros sino, como se afirma, por lo que es primero por sí o por naturaleza. De este modo, lo primero por lo que se comienza desde el punto de vista expositivo conceptual viene dado por lo que es común, un cierto universal, para luego referirse a lo particular, a lo que es primero para nosotros. En el caso de las artes poéticas, lo común es el carácter mimético de la poesía mientras que lo particular se refiere a las características específicas de cada una de estas artes ${ }^{10}$.

Además, entre los pasajes del corpus en donde el giro se repite, hay uno que merece una atención especial: el pasaje paralelo de Partes de los animales A $(P A)$. Entendemos que la conexión es trascendente puesto que en Partes de los animales el giro es utilizado dos veces (646a3-4 y 655b28ss) en el contexto de una serie de aclaraciones metodológicas que le dan un sentido bien específico y rico. Asumimos que aquellas prescripciones que especifican el giro pueden ser trasladadas a Poética puesto que poseen idéntico carácter metodológico-

\footnotetext{
${ }^{7}$ También se puede argumentar que en el proemio de Meteorológicos se utiliza, al igual que en Poetica 1

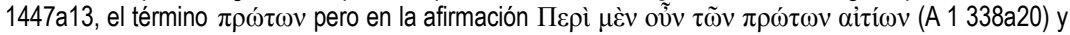
allí se conecta la investigación directamente con la búsqueda de las causas (i. e., se podría asumir que en incipit de Poetica, aitíwv se encuentra elidido).

${ }^{8}$ Cfr. Partes de los animales A 1 640a10ss con A 5 646a2ss, Refutaciones sofísitcas 14 164a21, Ética eudemia A 6 1217a18, Generación de los animales B 4 737b25, y otros giros semejantes en Ética a Nicómaco Z 4 1139b16, Física A 7 189b31 y Meteorológicos A 1 338a20. Barbero también reseña estas coincidencias $(2004,36)$.

${ }^{9}$ El tópico aparece en Física A 1, en Acerca del alma B 2, Metafísica Z 3 y Segundos analíticos A 2.

${ }^{10}$ En esta dirección los comentarios ad loc de García Yebra (1974), Barbero (2004) y Sinnot (2006).
} 
prescriptivo. Destaquemos en primer lugar un conjunto de interrogantes metodológicos presentes en Partes de los animales A 1. Aristóteles introduce dos preguntas íntimamente conectadas: en primer lugar, ¿se debe hacer una observación por géneros y luego las características específicas, o debemos estudiar cada especie por separado? (PA A 1 639b3-5) y a continuación, ¿se deben observar primero los fenómenos relativos a los animales y luego buscar el por qué y las causas o a la inversa? (PA A 639b 7-11). La respuesta ${ }^{11}$ del segundo interrogante va en línea con el conocido pasaje metodológico de Primeros Analiticos (APr) A 30 46a18-26 en donde se afirma que se debe proceder como los astrónomos: en primer lugar recoger los fenómenos relativos a cada cosa -así se obtiene la experiencia en astronomía- y sólo a continuación elaborar las causas y proceder con las demostraciones. Siguiendo esta misma lógica, Aristóteles contesta el primer interrogante -y tácitamente el segundo- señalando que debemos, en primer lugar, partir de la selección y recolección de las características relativas a cada género para, seguidamente, elaborar y proponer las causas y sobre la generación (PA A 1 640a13-15, también en A 4 644a25-6). Balme anota este pasaje señalando que claramente en contra de la crítica que le hiciera Bacon- Aristóteles sostiene que primero se debe contar con toda la información empírica para poder luego realizar afirmaciones generales. En esa dirección va también la crítica que le hiciera a Demócrito en Sobre la generación de los animales $(G A)$ E 8 788b11: según Aristóteles, Demócrito habría dado una explicación general sin examinar todos los casos. Contrariamente, una vez que se cuenta con una base empírica suficiente ${ }^{12}$, el procedimiento explicativo comienza, como hemos señalado anteriormente, por lo general y a partir de allí, abarcando lo particular. En efecto, la exposición científica debe respetar este orden para, por un lado, evitar las repeticiones innecesarias y, por otro, ayudar a conocer las causas comunes (BALME, 1992, p.72). Estas prescripciones metodológicas van en la dirección de la caracterización del método de salvar las apariencias puesto que, en efecto, el primer paso de dicho método consiste en la recolección de los fenómenos (las apariencias) para proceder luego con el segundo paso, su

\footnotetext{
${ }^{11}$ Esta respuesta la da el hombre culto (a diferencia del que sólo conoce el objeto específico). El hombre culto es quien conoce las reglas y principios que estructuran cualquier objeto (precisamente por tener un conocimiento general). Angioni enfatiza que el hombre culto es el filósofo y cree que esta distinción debe contrastarse con lo afirmado en Metafísica $\Gamma 1$ y E 1 sobre la ciencia universal y las ciencias particulares (cf. ANGIONI comm. ad loc). Cleary interpreta este pasaje de Partes de los animales de modo semejante (cf. CLEARY, 1994, p.67). Por otra parte, la discusión sobre los contenidos de la educación del hombre culto y la relación entre ésta y el conocimiento especializado de hechos tiene precedentes en Platón (Gorgias 485a; Protágoras 312b; Carta VII 340b y ss. (cf. MARCOS comm. ad loc).

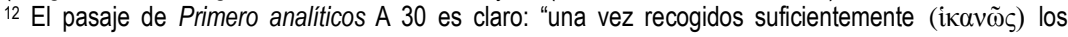
fenómenos, se encontraron las demostraciones astronómicas" (46a20-1).
} 
explicación ${ }^{13}$. De este modo, queda explicitado que no se puede proceder conforme a la naturaleza, i. e., de lo general a lo particular, si no se ha procedido en primer lugar de modo inverso, i. e., a partir de lo más conocido para nosotros y hacia lo común o universal. Si, entonces, se afirma que se procederá según el orden natural de la exposición, debemos suponer que existió con anterioridad un momento de selección exhaustiva y suficiente

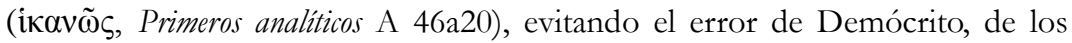
fenómenos pertinentes. Esta conclusión es sumamente relevante puesto que si el método es como el prescrito, debemos suponer entonces también para Poética una selección previa de los fenómenos necesarios para las explicaciones ulteriores.

La conexión entre Poética y Partes de los animales se termina de sugerir en el último capítulo de Partes de los animales A: el libro cierra con la misma afirmación de Poética: "Y sobre el método de investigación queda dicho esto; tratemos de explicar las causas respecto a las propiedades comunes y a las específicas, empezando ( $\dot{\alpha} \rho \xi \dot{\alpha} \mu \varepsilon v o t)$, como hemos establecido, primero por lo primero" (PA A 5 646a2-5, trad. Sánchez). Es significativo para nuestro fin que el método tenga las características prescritas y que, en el final de Partes de los animales A se afirme lo mismo que en Poética. Si, entonces, como regla metodológica general debemos tratar de explicar las causas comunes para luego ir hacia las específicas, así se afirma y se procede en Partes de los animales B- $\Delta$, podemos inferir un procedimiento semejante en Poética. ${ }^{14}$ Ahora bien, ¿cuál es la base empírica de Partes de los animales?, ¿cuáles son los paivó $\mu \varepsilon v \alpha$ de Partes de los animales? Curiosamente, o quizá no tanto, en Partes de los animales no contamos con un conjunto de $\varphi \alpha$ ivó $\mu \varepsilon v \alpha$ que constituyan base empírica alguna. Sin embargo, hay que destacar que si excluimos Partes de los animales A, el resto de Partes de los animales es un tratado explicativo. Los libros Partes de los animales B- $\Delta$ suponen la Historia animalium $(H A)$ puesto que, en efecto, es opinión común entre los investigadores de las obras biológicas de Aristóteles reconocer que $H A$ es el tratado donde se recoge la información relevante sobre la que luego se llevarán a cabo las explicaciones. Por otra parte, los

${ }^{13}$ Sin embargo, Cleary considera plausible la sugerencia de Kullman (1974) de que la distinción entre la recolección de fenómenos y la búsqueda de las causas se corresponde más cercanamente a la distinción en los Segundos Analíticos entre el conocimiento del hecho ( $\tau$ ò ö $\tau$ ) y el conocimiento de la

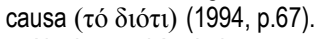

${ }^{14}$ Alguien podría dudar y pensar en la legitimidad de traspasar conclusiones de un texto a partir de la mera repetición de unas pocas palabras. El contraargumento es que en ambos casos son contextos de explicitación del proceder metodológico y que la distinción entre lo que es primero por sí/ por naturaleza y primero para nosotros es completamente estándar en Aristóteles. Si se defendiera una interpretación disonante con ésta, habría que brindar un buen argumento a su favor. 
tratados como Partes de los animales, De generatione animalium, De incessu animalium y De motu animalium son las obras en donde el estagirita se ocupa de construir las explicaciones del caso. De este modo, podemos considerar que lo mismo ocurre en Poética aunque, en este caso, no contamos con ningún texto donde se recojan los $\varphi \alpha$ ivó $\mu \varepsilon v \alpha$ tal como sucede con Historia Animalium. Quizá la explicación sea más simple de lo que se cree -aunque esto lo afirmo en tono meramente hipotético: en el caso de las investigaciones biológicas, la información brindada en Historia Animalium. es mayormente desconocida mientras que, en el caso del objeto de estudio de Poética, las obras mencionadas gozan, en su mayoría, de un amplio conocimiento.

Existen otros dos rasgos característicos de orden metodológico que también se destacan en Partes de los animales A y que nos permiten el contraste con Poética, a saber: en primer lugar, la investigación es una búsqueda de las causas (rasgo etiológico del quehacer científico). En los seres vivos, las causas son estudiadas en los distintos tratados ya mencionados. Como es sabido, el esquema de las cuatro causas suele reducirse a sólo dos por la identificación que acaece entre las causas eficiente, formal y final (a diferencia de los entes artificiales, cuyo fin es el producto del diseño de una inteligencia y distinto de ellos). En este sentido, debemos considerar cuál es la naturaleza del objeto de la Poética y, a partir de esto, reflexionar si debemos esperar, o no, que las causas estén claramente diferenciadas. En segundo lugar, en Partes de los animales A 2-3 Aristóteles, si bien acepta en general el método de la división, rechaza que ésta pueda ser realizada por una sola diferencia cada vez. Esta versión de la división, opuesta a la académica, da lugar a que los conjuntos, en razón de la cantidad de diferencias detectadas, puedan ser divididos en dos o más subgrupos. ${ }^{15}$ Es importante que critique así aquel uso de la división y que luego encontremos ejemplos de un tipo diverso de clasificación (así trabaja, de hecho, en Partes de los animales B, donde expone tres tipos de síntesis). Por ello, tal como vemos ese procedimiento en Partes de los animales B- $\Delta$, también deberíamos esperar encontrar lo mismo en Poética. En esa dirección continuaremos el examen.

Hasta aquí con las conexiones entre Poética y Partes de los animales tendientes a sugerir que subyace un mismo método en ambas obras. Si esta conexión es legítima, deberíamos encontrar, aunque más no de modo sugerido, la base empírica sobre la que está construida Poética. Avancemos en esta

${ }^{15}$ En su comentario ad loc, Balme dice que la crítica: "no es necesariamente contra la división en dos clases en cuanto tal, sino a la división de una diferencia por vez (sea en dos clases o más). En cambio, él [Aristóteles] recomienda dividir simultáneamente el conjunto por muchas diferencias, [...] Su método debe ser contrastado con toda clase de división hecha por una sola diferencia, sea dicotómica 0 politómica" (1972, p.101). 
búsqueda.

\section{\$2. Phainómena en Poetica 1-3}

Expondré ahora lo que podemos considerar los phainómena o la "base empírica" de las principales nociones de Poética a Poética 1-3, reservando Poética 4-6 para mostrar no sólo la "base empírica" sino también el modo en que allí se desarrolla la exposición de las causas de las artes poéticas. La búsqueda de los phainómena en que se asienta el tratado en su totalidad excede los límites de esta presentación. Por otra parte, no debe olvidarse que phainómena es un término que no está exento de ambigüedades ${ }^{16}$. Sin embargo, para nuestra presentación actual, es suficiente considerar que dentro de dicho término se encuentran no sólo los datos que nos brinda la sensopercepción -que en el marco del teatro viene dado por la música, las voces y los atuendos- sino también por aspectos relativos a los contenidos expuestos en las actuaciones sobre el escenario y presenciados por los espectadores. Ciertamente, el dato de la sensopercepción forma parte de la experiencia, pero también forma parte de ella el contenido de la actuación desarrollada por los actores. En efecto, un ateniense culto que asistía al teatro regularmente poseía lato sensu una experiencia suficiente, tanto del teatro como del resto de las artes poéticas, como para comprender sin dificultad aquello que Aristóteles expone en Poética. Quizá sea ilustrativa para esta noción de experiencia ampliada, la caracterización del buen discípulo en Ética a Nicómaco I 3 1195a3-5: no es buen discípulo quien no tiene experiencia (ä $\pi \varepsilon 1 \rho \circ \varsigma$ ) en las acciones de la vida y, la inversa, es buen discípulo el experimentado ${ }^{17}$. Así, no se trata sólo de tener opiniones o éndoxai sobre estas acciones sino haber experimentado las acciones mismas. De este modo, así como las acciones son la empeiría adecuada para el conocimiento de los principios de la ética es posible que el conocimiento de las distintas artes poéticas en tanto experiencia vivida constituya la empeiría sobre la que se asienta Poética. Esa experiencia vivida puede darse de dos modos: tanto por escuchar un relato mítico en la tradición oral (que luego puede aparecer en una obra) como por la asistencia al teatro y la visión de las obras allí expuestas. En este sentido consideramos que existe una "base empírica" compartida -y perfectamente explicitable- que sirvió de punto de partida para la elaboración que hizo Aristóteles de su teoría poética. Como hemos señalado, defendemos

16 La polémica se remonta a la ya mencionada tesis de Owen (1961) sobre la identificación entre phainómena y éndoxa. Un examen crítico de Owen en Berrón (2013).

17 También puede ofrecerse como ejemplo la célebre distinción entre el empírico y el técnico de Met A 2. Recordemos que el empírico es el que conoce las cosas por haber tratado con ellas, por haber tratado con lo particular y, así, el empírico conoce los materiales por haber construido. Es lícito elaborar un paralelo entre, de una parte, el obrero y el espectador, y de otra entre el técnico y el dramaturgo. 
que Poética está construida sobre phainómena a partir de los cuales se realizan las distinciones, se establecen las causas y, como en cualquier otra técnica, se resuelven los posibles problemas. ${ }^{18}$ Avancemos en esa dirección.

Poética 1 presenta variada información que puede ser considerada como la base empírica sobre la que se elabora la explicación teórica. Luego del incipit, nos encontramos con una primera enumeración de seis formas de poesía que tienen como rasgo común ser tipos de mímesis: la (i) epopeya, (ii) la poesía trágica, (iii) la comedia, (iv) la poesía ditirámbica, (v) la aulética y (vi) la citarística son mencionadas y consideradas como la base empírica ${ }^{19}$ que permite identificar lo común a todas ellas: ser casos particulares de mímesis. Además, esta enumeración ofrece una serie de criterios que permiten encontrar las diferencias, i. e., identificar sus especies: 1) por el medio, 2) por el objeto, y 3) por el modo en que realizan la mimesis ${ }^{20}$. En 1447 a20 se señala también que las imitaciones o representaciones son realizadas por arte o por costumbre ( $\delta i \grave{\alpha}$

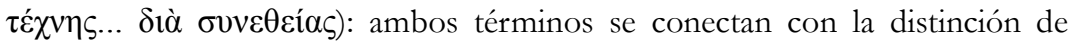
Metafísica A 1 y Ética a Nicómaco $\Theta 6$ 1158a14-5 donde se explica que el técnico posee el conocimiento causal mientras que el hombre de experiencia tiene el conocimiento de lo particular. De este modo, se asume que hay un universo de particulares que habilita la posibilidad de personas experimentadas, i. e., que poseen empeiría, y también, que en base a esta experiencia puede haber un conocimiento técnico.

Otro elemento a ser destacado en este pasaje es que las dos divisiones que se presentan, a saber: la mimesis en seis tipos de artes poéticas y los tres criterios en que puede ser realizada la mimesis, nos muestran que no se sigue la

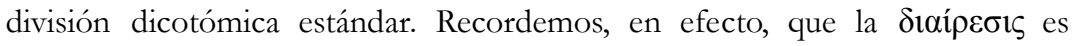
criticada en $P A$ A 2-5 y que Aristóteles indica en Segundos analíticos B $1396 \mathrm{~b} 25$

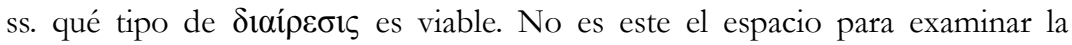

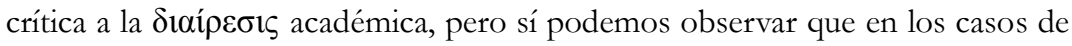
divisiones presentados se está procediendo de un modo original y propio de

${ }^{18}$ Esta última afirmación apunta al resto de Poética (i. e., Poet. 7-22). Por razones de espacio no tratamos todo el texto sino que nos concentramos en Poética 1-6; sin embargo, consideramos que en los capítulos subsiguientes, Aristóteles se vale de los desarrollos previos para, precisamente, resolver las dificultades. El desarrollo de este punto es materia de otro trabajo.

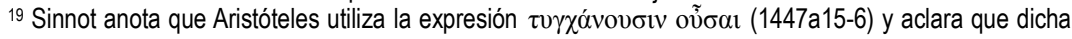
expresión "connota que se trata de una circunstancia de hecho cuya necesidad no puede aclararse 0 justificarse". Esto refuerza el carácter de factum que posee el contenido de tal información (cf. SINNOT, 2006, n. ad loc.).

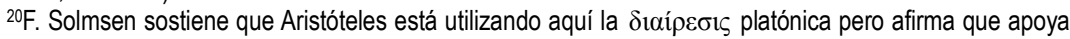
esta división en observaciones históricas (o especulaciones históricas) (1935, p.199). Lo relevante de la

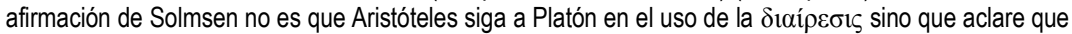
las diferencias fueron obtenidas a partir de observaciones (aunque por momentos algo especulativas) históricas. 
Aristóteles (particularmente por la posibilidad de dividir cada grupo en más de dos subgrupos). Solmsen presenta un esquema que muestra el proceso de la división donde puede apreciarse el modo no platónico de su procedimiento $(1935,191)$.

El resto de Poética 1 se ocupa de precisar e ilustrar el primer criterio que sirve para distinguir entre las distintas artes miméticas (i.e., el medio por el cual imitan). Así, se afirma que todas lo hacen por el ritmo, el lenguaje y la armonía, de forma separada o mezclada y, a continuación, se ponen los ejemplos que sirven de prueba para la afirmación: (1) la aulética y la citarística (también la siringa) utilizan la armonía y el ritmo; (2) "la de los bailarines" utiliza sólo el ritmo; (3) otra, sin nombre común (dado que abarca los mimos de Sofrón y Jenarco, los diálogos socráticos, los versos trímetros y los versos elegíacos) utiliza sólo la palabra; ${ }^{21}$ por último, (4) el ditirambo, el nomo, la comedia y la tragedia se valen de los tres medios de imitación (aunque unas lo utilizan al mismo tiempo y otras los usan por separado). Naturalmente, la presentación del criterio se realiza en primer lugar, es decir, primero se propone el criterio para luego "distinguir" entre las distintas artes. Sin embargo, es claro que la elaboración del criterio es el resultado de la consideración de un cierto conjunto de casos que permiten construirlo pero que, en este orden expositivo, aquellos casos que permitieron elaborar el criterio ahora se vuelven ejemplos que lo ilustran. Lo mismo con los criterios ulteriores.

Poética 2 se ocupa del segundo criterio: el objeto imitado. Aristóteles

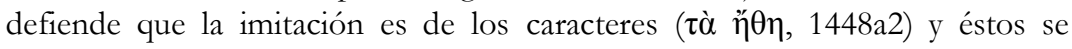
distinguen, según la virtud o el vicio, en buenos o malos. Pero dicha imitación se hace volviendo el objeto imitado mejor o peor, o imitándolo igual. Prueba de ello es que, entre los pintores, Polignoto los representa mejores, Pausón peores y Dionisio semejantes. Se destaca que la división no sea en dos grupos sino en tres. ${ }^{22}$ Es evidente que ( $\delta \tilde{\eta} \lambda o v$ $\delta \dot{\varepsilon}$ ö $\tau$, 1448a7) estas diferencias

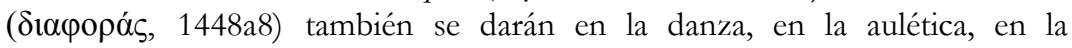
citarística, en la prosa y en los versos: Homero los representa mejores,

\footnotetext{
${ }^{21}$ Aristóteles aclara que los hombres llaman según el tipo de verso a unos poetas elegíacos y a otros poetas épicos, etc. (1447b14). Aclara luego que son poetas tanto Homero como Empédocles pero que al segundo habría que llamarlo propiamente fisiólogo.

${ }_{22}$ Castillo Merlo reseña la dificultad existente entre los interpretes a la hora de resolver esta tercera subdivisión (porque estaría en contra de la división en dos grupos). Es interesante que afirme que "Aristóteles parece verse forzado por las propias prácticas artísticas de su época a introducir una tercera posibilidad (...)" (CASTILLO MERLO, 2016, p.66) porque muestra, una vez más, que Aristóteles estaría tomando en cuenta la preeminencia de la información empírica. Por otro lado, la discusión de fondo sobre si debe dividirse el objeto en dos o en tres está reseñada en el artículo de Castillo Merlo así como también en el libro de Suñol (cf. SUÑOL 2012, p.59).
} 
Cleofonte, semejantes, Hegemón y Nicócares, peores. ${ }^{23}$ Por último, la tragedia imita a los hombres mejores mientras que la comedia a los peores, pero en ambos casos, mejores o peores de lo que son en realidad. Debe notarse que toda la información brindada es conocida: la división de los caracteres en buenos y malos, las representaciones "mejores", "iguales" o "peores", que esto mismo pasa en la danza y el resto de las artes, también lo que hacen Homero, Cleofonte y el resto así como el tipo de imitación de la tragedia y de la comedia, todo, en conjunto, sirve para inferir que hay mímesis de cosas diversas, $i$. e., de objetos diversos. De este modo surge el criterio, de la observación de las diferencias, pero una vez que contamos con tal criterio, podemos continuar distinguiendo casos nuevos. Sin embargo, el criterio surge de los casos, no al revés; sólo luego, en efecto, servirá para explicarlos ${ }^{24}$.

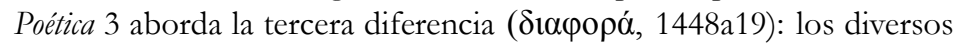
modos. El primer modo es el (1) narrativo que se subdivide (a) por el estilo directo, a la manera de Homero, o (b) el indirecto (no hay ejemplo aquî) y (2) la dramática (dice Aristóteles: como si todos obraran y actuaran realmente). No se esfuerza Aristóteles demasiado en justificar estas distinciones pero la razón seguramente radica en que las considera manifiestas. ${ }^{25}$ Luego se ocupa someramente de mostrar que los criterios (i), (ii) y (iii) pueden utilizarse para clasificar, y así reunir o separar, generando diversas combinaciones. Por ejemplo, Sófocles imita como Homero al imitar hombres buenos, pero imita como Aristófanes al imitar a quienes actúan y obran. ${ }^{26} \mathrm{El}$ capítulo cierra con una disquisición histórica y etimológica sobre el origen del nombre de la comedia. Tal como con el segundo criterio, Aristóteles ilustra el modo en que funciona el criterio, pero es bastante claro que estos mismos casos son los que sirvieron para la elaboración del criterio en cuestión. Continuemos con el tercer momento de nuestra exposición donde veremos tanto la exposición de las cuatro causas de las artes poéticas como su apoyo empírico.

\footnotetext{
${ }^{23}$ Aristóteles menciona también a Argas, Timoteo y Filoxeno, pero no aclara cuál es el modo en que éstos imitan.

${ }^{24}$ He utilizado "inferir" y "surgir" para referirme al modo en que se establecen las diferencias. Se podrían estudiar estos pasajes como un ejemplo de lo que Aristóteles consideraría un tipo de inducción

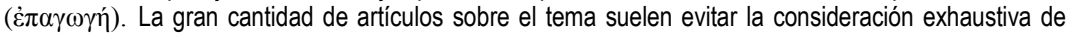
pasajes de este tipo los que, sin embargo, podrían ayudar a aclarar la relación entre los particulares y el universal (cf. ENGBER-PEDERSEN, 1979, p.302).

${ }_{25}$ Con todo, hay otros modos de distinguir dentro de la poesía imitativa, tal como el mismo Platón lo observa en República X,603c. Cuando decimos que "las considera manifiestas" asumimos que hay un contexto de discusión en donde Aristóteles ha esclarecido dichas distinciones y que, a la hora de exponerlas, se limita sólo a utilizarlas (sin justificarlas).

${ }^{26}$ Recuérdese que Aristófanes es comediógrafo y, como tal, imita a los hombres peores haciéndolos peores.
} 


\section{\$3. Las causas en Poética 4-6}

Estos capítulos tienen un valor especial porque asumen el fenómeno según el conocido esquema causal propuesto por el estagirita. En este sentido, no deja de ser sorprendente que tanto García Yebra como Sinnot no comentan nada sobre la presencia de la doctrina de las causas en estos pasajes. No obstante, creemos particularmente valioso examinar estos capítulos bajo la perspectiva de las cuatro causas dado que esto pone en evidencia el cuidado que Aristóteles tiene en su investigación sobre la creación poética por considerar a esta como una genuina técnica. Veamos las causas en la Poética.

La causa eficiente. El lugar donde la introduce corresponde a Poética 4 y, aunque evitaremos citar pasajes extensos, consideraremos casi todo el capítulo en lo que sigue. En las primeras líneas de Poética 4 Aristóteles afirma que expondrá dos causas de la poética ( primera, condición común y propia de las artes poéticas, consiste en la

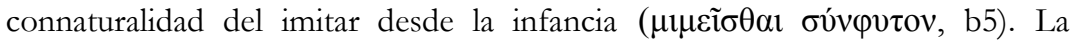
connaturalidad del imitar debe entenderse como formando parte de la naturaleza del hombre y, bajo este supuesto, dado que está en la naturaleza de cada uno, desde el momento de comenzar a vivir, "desde niños" aduce más adelante Aristóteles, esta naturaleza nos impele a imitar. No conviene olvidar que en numerosos lugares se define a la naturaleza como el principio del movimiento (particularmente en Phys B 1 192b20-3) ${ }^{27}$. Así, podemos asumir que el hecho de esta connaturalidad supone que en los hombres se da la naturaleza en este sentido. De ese modo, Aristóteles aclara que el hombre es el mejor dotado para la imitación y que adquiere sus primeros conocimientos a través de ella (1448b6-8). Se destaca el carácter de potencia que tiene la condición de imitar en el hombre pero, además, su actividad espontánea o natural (y no forzada). Ambos ejemplos confirman que el imitar tiene el carácter de causa motriz puesto que es por su intermedio que, por ejemplo, comienza en los niños el aprendizaje. De modo inverso, se supone que la ausencia de la capacidad de imitar sería un serio problema para el inicio del aprendizaje y, por esta razón, se vería confirmado su rasgo causal. Ciertamente, aunque Aristóteles no lo diga explícitamente, es bastante patente entonces que el imitar es, bajo las consideraciones precedentes, el principio desde donde

\footnotetext{
${ }^{27}$ La definición de Física B 1 dice que la naturaleza es principio en tanto es causa del movimiento o del reposo en la cosa a la que pertenece primariamente y por sí misma, no por accidente. No debe perderse de vista que Aristóteles define naturaleza de distintas maneras, particularmente en Metafísica $\Delta 4$. Allí es definida, entre otras acepciones, no sólo como causa motriz sino también como causa material, como la

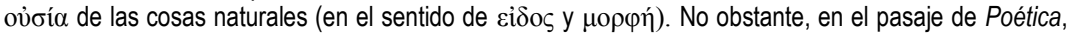
es claro que el sentido aludido es el de causa eficiente.
} 
procede el movimiento, i. e., la causa motriz.

En lo que concierne a la segunda de las causas mencionadas, existe una polémica. Al comentar las líneas 1448b4-5, Yebra anota que hay dos lecturas sobre la posible segunda causa: unos afirman que se trata del agrado ( $\tau$ ò $\chi \alpha$ ípeıv, b8) mientras que otros defienden que se trata de la connaturalidad del ritmo y la melodía (b20-1) ${ }^{28}$. No es éste el espacio para repasar pormenorizadamente los argumentos de unos y otros. Sin embargo, brindaremos algunas razones por las cuales el agrado no puede ser considerado ni causa eficiente en particular ni causa en general. En primer lugar, no puede ser considerado causa eficiente porque, a todas luces, el agrado (o el placer) es un tipo de resultado ${ }^{29}$. Si esto es correcto, el agrado debería ser considerado antes que como causa eficiente, como un tipo de causa final. Además, si consideramos otras afirmaciones sobre el placer como las que aparecen en EN $Z$ donde éste es definido como una actividad del modo de ser conforme con la naturaleza (1153a14), la caracterización del placer como fin es bastante fuerte $^{30}$. El trato que recibe el placer entendido éste como un bien en EN Z nos impele a considerarlo un tipo de fin y, dado este examen, es imposible que pueda ser una causa que origine o genere, en tanto causa eficiente, la tragedia. Ahora bien, si descartamos la posibilidad de que sea causa eficiente, ¿se trata entonces de una causa final? Veámoslo.

El principal argumento de quienes comprenden al agrado como causa está en el texto aristotélico: tomemos en cuenta que afirma, luego de mencionar la connaturalidad del imitar, que "todos hallan agrado en las imitaciones" (b8-9) y por ello éste sería la segunda causa. A continuación, afirma que tenemos signos de ello ( $\sigma \eta \mu \varepsilon i ́ o v, ~ b 9)^{31}$ en lo que ocurre ( $\sigma u \mu \beta \alpha$ ivov, b9): el agrado es un fenómeno que constatamos como resultado de contemplar imágenes, incluso imágenes de cosas que, de tenerlas presentes

${ }^{28}$ Entre los primeros: Ritter, Bywater, Rostagni y Hardy; entre los segundos: Vahlen, Gudeman y Else. Yebra también se inclina por la segunda opción.

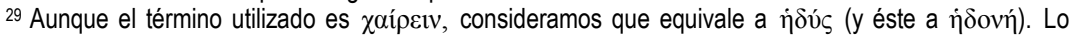
prueba el hecho de que existe un pasaje paralelo en Retórica A 1371b4-10 donde -utilizando prácticamente los mismos términos que en Poética 4- se informa que aprender ( $\mu \alpha v \theta \alpha ́ v \varepsilon v v$ ) es

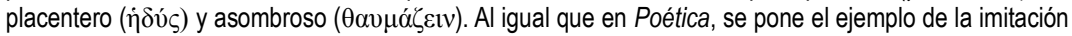
de las bestias y se informa que en la imitación se da un tipo de razonamiento y se logra aprender algo. Barbero estudia detalladamente la relación entre Poética y Retórica (cf. BARBERO, 2004, p.139-42).

${ }^{30}$ Para una discusión de la naturaleza del placer entendida ésta como actividad o perfeccionamiento de la actividad, nos remitimos a Bieda (cf. BIEDA, 2005, sección I. b).

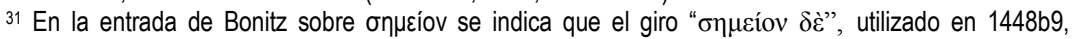
significa que lo presentado es indicio a partir de lo cual algo es reunido (colligatur) (1870, p.677). La conexión con otros pasajes donde lo que se considera indicio tiene una cercanía con la sensopercepción muestra que Aristóteles considera tanto a lo estrictamente sensible como a estos casos como una base adecuada para establecer diferencias. 
directamente, tales como bestias y cadáveres, no tendríamos ninguna satisfacción. Explicando la razón (aî́tov, b12) del agrado producido en el imitar, Aristóteles afirma que todos los hombres sienten satisfacción al aprender ( $\mu \alpha v \theta \alpha ́ v \varepsilon ı v$, b13) y señala también que al contemplar las imágenes se aprende así como se deduce ( $\sigma 0 \lambda \lambda \sigma \gamma i \zeta \zeta \varepsilon \sigma \theta \alpha 1$, b16) qué es cada cosa. Con esta aclaración se establece por qué causa sentimos agrado, pero también queda claro que lo que persiguen los hombres no es el agrado mismo sino el aprender o el deducir y que estas actividades son las que, a la postre, producen el agrado. Por ello, debemos evaluar que Aristóteles considera al placer como un fenómeno que perfecciona la actividad ${ }^{32} \mathrm{y}$, a partir de esto, podemos pensar que el agrado que acontece con la imitación no es más que una sensación o sentimiento que está unida al imitar, sin ser el propio imitar. Si esto es así, aunque no puede considerárselo separado, no puede ser tomado propiamente como el fin del imitar. Es bastante claro por qué Aristóteles pone en conexión el imitar con el agrado, pero también es claro que esto no implica que el agrado sea el fin por el cual se llegaron a generar ( $\gamma \varepsilon v v \tilde{\eta} \sigma \alpha 1,1448 b 4)$ las artes poéticas. Y siendo esto así, el agrado no puede ser tomado como causa final aunque sí como un epifenómeno que sucede luego de realizada la imitación. Un argumento complementario a los anteriores es que Aristóteles se ocupa de establecer con precisión cuál es la causa final de las artes poéticas cuando trabaja particularmente el fin de la tragedia. Si bien lo veremos más adelante, Aristóteles dice expresamente que la trama y el orden de los hechos constituyen la finalidad de la tragedia (cf. Poet. 1450a15-24). Cuando expongamos sobre la causa final volveremos sobre este pasaje, por ahora es suficiente con señalar que el agrado no puede ser fin porque Aristóteles dice explícitamente qué tipo de fin debemos buscar al exponer y presentar el fin propio de la tragedia. Como resultado de este examen, excluimos al agrado como una de las dos causas invocadas y de este modo, nos inclinamos a considerar que la segunda opción debe ser tomada como la correcta.

La segunda causa eficiente corresponde, entonces, a la connaturalidad del ritmo y la melodía (b20-1). Dice Aristóteles: “[...] al comienzo los que tenían una disposición natural para esas cosas fueron haciéndolas avanzar de a poco y dieron origen ( $\dot{\varepsilon} \gamma \varepsilon ́ v v \eta \sigma \alpha v)$ a la poesía a partir de las improvisaciones." (b22-4). Los hombres en los que el ritmo y la melodía se presentan como disposiciones naturales espontáneas y para quienes su cultivo resulta fácil son, según se sigue de lo anterior, aquellos que dan origen a las primeras

32 "El placer perfecciona la actividad" (cf. Ética a Nicómaco K 4 1074b30). Sin embargo, se aclara allí mismo que el surgimiento del placer está condicionado a que la facultad que realiza la acción lo haga del modo adecuado y, sólo así, habrá placer. 
imitaciones y, a fin de cuentas, a las formas más evolucionas de las artes poéticas, particularmente a la poesía y a la música. Al igual que en la consideración de la primera causa eficiente, esta segunda, que de hecho no consiste en otra cosa que en un tipo especial de mímesis, es una condición que debe estar presente en el origen del movimiento y que, ciertamente, lo impulsa. No se trata de una finalidad sino de una peculiaridad de la naturaleza de los hombres que impulsa en estos, que genera en esto, las imitaciones y, así, el origen de las artes miméticas.

Una última consideración sobre Poética. 4 que nos permite visualizar el camino hacia el establecimiento de la causa formal. Una vez que se establecen las causas que dan origen a las artes poéticas, lo razonable es exponer cómo fue el desarrollo ulterior. De ese modo, el texto continúa con la historia de la tragedia y todo el pasaje es relevante porque muestra, apoyada en mucha información, la lectura teleológica de esta historia. En tono hipotético se afirma que la poesía tiene su origen remoto en ciertas improvisaciones que luego se orientan a la imitación de los caracteres: las invectivas imitaron el carácter malo y los himnos y encomios los buenos. No se conserva nada anterior a Homero, pero sí el Margites. Estas obras tomaron el metro yámbico y se llamaron por ello, luego, yambos. Hubo así poetas de obras satíricas (yambos) y poetas de obras heroicas. Aristóteles afirma también que Homero, con la escritura de la Ilíada y la Odisea anticipó la tragedia, pero también, con la escritura del Margites anticipó la comedia. ${ }^{33}$ De este modo, con el advenimiento de la tragedia y de la comedia, los poetas épicos se convirtieron en poetas trágicos y los poetas yámbicos en comediógrafos (1449a2-6). Aristóteles considera que ya se dijo suficiente sobre la especie ( $\varepsilon i \delta o \zeta, 1449$ a 8$)$ y pasa a considerar el grado de evolución del teatro. El origen está, como ya afirmó, en una improvisación: la tragedia nace como improvisación de los exarcontes del ditirambo y la comedia de la improvisación del exarconte del canto fálico y, señala Aristóteles: "la tragedia creció.... y se detuvo, cuando alcanzó la naturaleza que le es propia" ( significativo puesto que introduce el finalismo en clara conexión con la causa formal: la evolución de la tragedia -que se desarrolla a continuación- culmina con la forma que actualmente tiene y que, como causa formal y final, orientó el desarrollo en esa dirección. Así lo explica Aristóteles: (1) Esquilo elevó el número de actores de uno a dos, (2) redujo el coro y (3) convirtió el diálogo en la parte principal (en desmedro del coro). Sófocles (4) introdujo al tercer actor

${ }^{33}$ Dice Aristóteles que las obras de Homero tienen carácter dramático (por ello serían antecedentes de la tragedia) pero también afirma que el Margites habría imitado lo risible (antes que tratarse de una invectiva, que sólo se ocupa de satirizar o maldecir) (cf. Poética 4 1448b34ss). 
y (5) la escenografía. (6) Aumentó de tamaño y calidad en desmedro de la pequeñez y la expresión risible; (7) se trocó el tetrámetro por el verso yámbico. ${ }^{34}$ Observemos que, aun cuando esta información apunta en general a reconstruir la historia del teatro en un sentido finalista, no debe perderse de vista que esta descripción conforma un importante volumen de información, de apoyo empírico, que más adelante servirá propiamente para elaborar la definición de la tragedia. Es sumamente relevante que se informe todo esto porque vuelve visible lo que Aristóteles tiene en mente a la hora no sólo de definir la poética y sus especies sino también, principalmente, la información sobre la que se apoya.

La causa formal. Detengámonos ahora en Poética. 6, particularmente en la célebre definición de tragedia. Antes de exponer la definición Aristóteles dice que a partir de lo que ha desarrollado previamente (1449b22-3), se puede

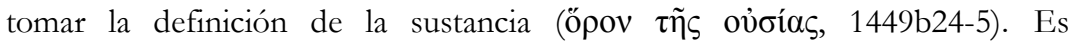
destacable que Aristóteles afirme que la definición se apoya en lo que se dijo previamente puesto que lo anterior sirve, en efecto, de base para la misma. Al anotar este pasaje, Yebra señala los lugares donde se anticipan las características que están recogidas en la definición y, ciertamente, la mayoría de ellas se encuentran presentes. Sinnot sostiene, por su parte, que no todos los elementos de la definición tuvieron su desarrollo explícito (cf. SINNOT, 2009, p.43, n.130). De todos modos, podemos encontrar en los desarrollos ulteriores una prueba de que la definición que se está brindando tiene en cuenta todo el universo fenoménico que gira en torno a la tragedia y que quizá sólo en razón de la exposición actual no encontramos toda la información expuesta antes de la definición. De este modo, el apoyo empírico sobre el que se establece la definición está presente o bien en la exposición precedente o bien en lo que sigue, pero en ningún modo carecemos de dicha base. Hay buenos elementos textuales para suponer que la exposición aristotélica se apoya en información constatable y disponible para el lector estándar.

Antes de avanzar en el examen de la definición de tragedia, recordemos cómo se caracteriza la causa formal en Física: [causa formal] es "la forma o el modelo, esto es, la definición del que era ser y sus géneros [...] y las partes de la definición" (Física B 3 194b26-7). ${ }^{35}$ La forma, o especie si pensamos en una opción para traducir tò عĩos, es la causa que equivale a la

34 Se ha criticado largamente a Aristóteles por la presentación "parcial" y "sesgada", incluso "especulativa", "apriorística" o "metafísica" de los datos. Con todo, debe tenerse en cuenta que Aristóteles no está aquí discutiendo la historia sino desarrollando una exposición sistemática del tópico en cuestión.

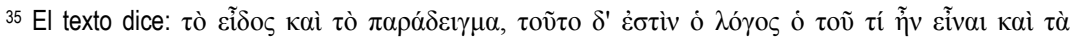

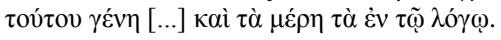




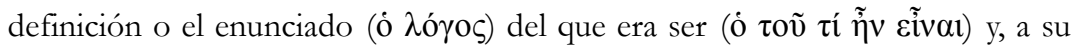
vez, este enunciado debe incluir las partes del enunciado que define ( $\tau \dot{\alpha} \mu \varepsilon \dot{\varepsilon} \rho \eta$ $\tau \grave{\alpha} \dot{\varepsilon} v \tau \tilde{\varphi} \lambda \hat{\gamma} \gamma()^{36}$. Esta caracterización es relevante porque en ella se estipula que una definición debe incluir los distintos géneros dentro de los cuales se incluye el objeto definido; su vez, estos géneros constituyen cada una de las partes de la definición. Si éste es el modelo a seguir para detectar el correcto establecimiento de una definición, podemos tomarlo entonces como criterio y ver si la presunta definición de la tragedia cumple con ellos. Las líneas 1449b24-5 nos aseguran que allí está la definición, considerémosla.

La tragedia es, pues, imitación de una acción noble y completa, que tiene extensión, con lenguaje sazonado con cada especie en particular y en las distintas partes; actuando y no a través de un relato; y que por medio de la conmiseración y el temor produce la purificación de esas afecciones. ${ }^{37}$ (Poet. 6 1449b24-8, mi traducción).

Un primer punto a tener es cuenta es que la tragedia es un producto poético que se incluye dentro del género superior y común de las imitaciones. En efecto, en las primeras líneas de Poética Aristóteles afirmó que hay distintos tipos de artes poéticas que tienen como rasgo común el ser todas ellas imitaciones. A continuación, se destaca el tipo específico de objeto imitado: la

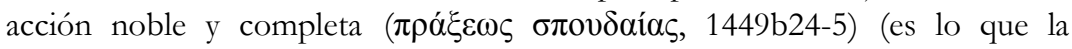
diferencia de la comedia por el objeto, que corresponde al segundo criterio de demarcación entre las especies de mímesis). Este no es un rasgo común sino que constituye el rasgo que caracteriza propiamente a la forma (દĩ $\delta$ os) de la tragedia. De este modo, en esta primera parte de la "definición", tenemos el género superior y la diferencia última que conforman, propiamente, la definición. En adelante, Aristóteles introduce las partes ( $\tau \grave{\alpha} \mu \varepsilon \dot{\varphi} \rho \eta$ ) que conforman el resto de la definición. En efecto, el desarrollo subsiguiente presenta los géneros subordinados dentro del género superior de la mímesis. Así, Aristóteles aclara cuáles son los géneros intermedios, a saber: 1) la completud, 2) la extensión, 3) el lenguaje sazonado, 4) la actuación y el no relato. Queda excluido el efecto producido, la purificación, puesto que esto no es propiamente un género sino un tipo de consecuencia particular. Queda también excluido de la definición la aclaración que le prosigue (allí donde se especifica qué se entiende por lenguaje sazonado). Excluyendo estos aspectos

\footnotetext{
${ }^{36}$ Algo semejante afirma Aristóteles en Metafísica $\Delta 25$ 1024b22-24. Angioni comenta ad loc que con este giro se reportan los ingredientes lógicos que están comprendidos en una definición (2013, comm. ad loc).

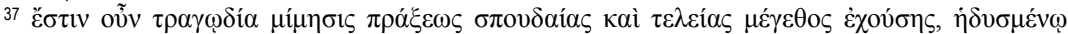

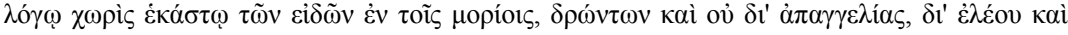

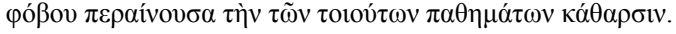


no esenciales, la definición queda así: la tragedia es una imitación completa y extensa, con lenguaje sazonado y por medio de la actuación de una acción noble. Para visualizarlo más claramente:

$\begin{array}{ll}\text { Género superior: } & \text { imitación, } \\ \text { subgénero 1: } & \text { completud, } \\ \text { subgénero 2: } & \text { extensión, } \\ \text { subgénero 3: } & \text { lenguaje sazonado, } \\ \text { subgénero 4: } & \text { actuación, } \\ \text { género específico: } & \text { acciones nobles. }\end{array}$

De este modo, observamos que Aristóteles cumple con su prescripción de exponer los términos (őpol) de la sustancia (ov̉oía) en cuestión tal como había anticipado en 1449b24-5. A su vez, los términos expuestos dan cuenta de la definición de modo exhaustivo puesto que se incluyen el género superior, la diferencia específica y los géneros intermedios que son, como se afirma en Física B 3 194b24-7, las partes que integran el enunciado de la definición. De este modo, Aristóteles cumple con sus propias exigencias.

Hay, sin embargo un ítem más que una definición debe cubrir, que no hemos considerado aquí y que refiere a la capacidad explicativa de una definición. El método de "salvar las apariencias" se completa con la explicación de los fenómenos en cuestión. Nuestro trabajo cubre sólo hasta el establecimiento de las causas, en este caso la formal, y así queda cubierto el fenómeno de la tragedia en cuanto a sus causas, pero si el procedimiento es completo, el paso subsiguiente es explicar apariencias o fenómenos involucrados dentro del marco de la tragedia que resultan, en principio, aporéticos. Este paso es relevante puesto que supone el "uso" de la definición como principio explicativo. En nuestra consideración general del método de "salvar las apariencias" entendemos -y así completamos la visión de Cleary que presentamos en la introducción- que este aspecto no sólo se encuentra incluido dentro del método sino que constituye un paso clave del mismo. Ciertamente, el uso de la definición como principio conforma el momento demostrativo o explicativo en el que la definición se valida como genuina definición. La definición es, primeramente, el resultado de un proceso parcialmente inductivo que se apoya en una base empírica -en sentido amplio- y que alcanza legitimidad como principio en la medida en que puede actuar como tal, esto es, siendo premisa de demostraciones (explicaciones). Nuestro examen actual no cubre, en razón del espacio, este aspecto pero defendemos que en el resto de Poética Aristóteles lleva a cabo este trabajo y revalida así las causas establecidas en general y la causa formal en particular.

La causa final. Aristóteles caracteriza a la causa final como "aquello 


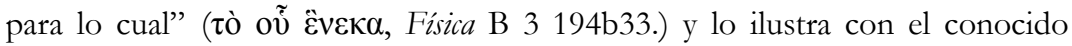
ejemplo de la salud como causa del pasear. También incluye allí al adelgazar, la purgación, los fármacos y los instrumentos quirúrgicos como diseñados y

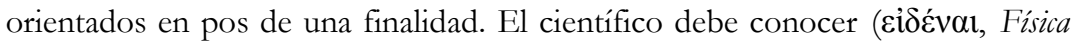
B 7 198a22) las cuatro causas para poder construir demostraciones ( $\dot{\alpha} \pi \delta \delta \omega ́ \sigma \varepsilon 1$, a24), sin embargo, muchas veces sucede que tres de estas causas se identifican. Como es sabido, las causas eficiente, formal y final vienen a ser, especialmente en los casos de la generación natural, las mismas. En el caso "hombre engendra a hombre" (198a25-6) ocurre una coincidencia en la especie y, del mismo modo, ocurre en el resto de los casos de la generación de los vivientes. Así entonces el que genera es hombre, lo generado es hombre y el fin es hombre. En el caso de la generación de la técnica, como es el caso de la salud, coincide el conocimiento técnico que está en el alma del agente, la salud buscada como fin y la forma alcanzada en el paciente. Algo semejante podemos pensar para el caso de la poesía trágica: hay un conocimiento de la forma o definición presente en el dramaturgo, hay una forma en la obra y una forma buscada en la elaboración de la tragedia. Veamos qué dice Aristóteles en Poética.

Para introducirnos en la causa final de la tragedia debemos abordar el concepto de trama $(\mu \tilde{v} \theta$ os): "la trama es la imitación de la acción, pues llamo trama a la composición de los actos". ${ }^{38}$ La caracterización de la trama en este sentido es relevante porque se estipula que la imitación de la acción (lo que define a la tragedia) está dada en la trama misma. No hay nada más allá de la trama que pueda cumplir con lo que es propiamente una tragedia. Es claro que hay otros aspectos que son condición de la tragedia (más adelante veremos la causa material), pero es la composición de las acciones lo que hace que una obra sea una tragedia, y no otra cosa. Aristóteles distingue en este pasaje entre la trama y los caracteres ( $\tau \grave{\alpha} \delta \grave{\varepsilon} \ddot{\eta} \theta \eta$ ) y establece que la trama es condición sine qua non para la tragedia, mientras que los caracteres no son indispensables. Por otra parte, sugiere que los caracteres son elaborados y representados por los

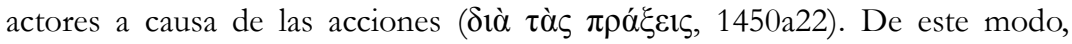
afirma taxativamente: "los actos, es decir, la trama, son el fin de la tragedia, y en todas las cosas el fin es lo más importante". ${ }^{39}$ Estos primeros argumentos evidencian fielmente que la trama es considerada como el fin que rige la estructura general de la tragedia y, en dicho marco, también la configuración de

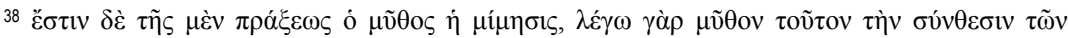
$\pi \rho \alpha \gamma \mu \alpha ́ \tau \omega v$, (Poética 6 1450a3-5, mi traducción).

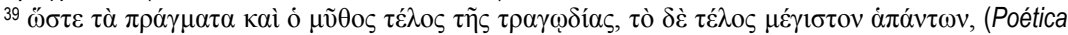
6 1450a22-23, mi traducción).
} 
los caracteres. El bagaje conceptual teleológico de Aristóteles está operando en la caracterización de la tragedia y el lugar del fin está reservado a la trama de modo que el resto de los elementos se convierten en fines intermedios y condicionados en vistas del fin último.

Dos aportes más en esta dirección: por un lado, afirma que la causa que produce y conduce la sensibilidad del espectador ( $\psi v \chi \alpha \gamma \omega \gamma \varepsilon \tilde{\mathbf{u}}, 1450 \mathrm{a} 33$ ) es, precisamente, la trama. Es relevante que la trama "conduzca" al alma en la orientación adecuada, i. e., en dirección al fin último, para que así pueda visualizarse íntegramente la tragedia. Además, si debe haber purgación y el conjunto de emociones involucradas en dicho fenómeno, es necesario que la trama esté adecuadamente constituida. Con esto se vuelve a poner de manifiesto la centralidad de la noción y, especialmente, su condición de fin. A

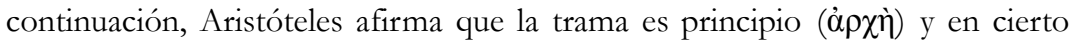

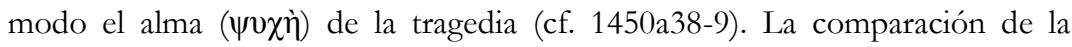
trama con el alma de la tragedia se ejemplifica con la analogía de la pintura: los colores son los caracteres y la trama es el dibujo ( $\gamma \rho \alpha \varphi \iota \kappa n ́ s, 1450 b 1)$. Según esta comparación, el sentido de la pintura sólo existe en el dibujo, tenga o no colores y, correlativamente, si una pintura tiene sólo colores, no produciría el mismo regocijo que conteniendo también el dibujo, i. e., el equivalente a la trama. Además, si tenemos presentes dos caracterizaciones del alma en $D e$ anima, a saber: como forma ( $\dot{\omega} \varsigma$ عĩoos, 412a20) y como actualidad primera

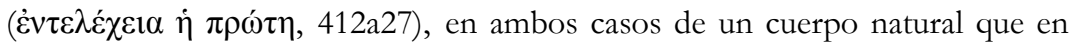
potencia tiene vida, y que la vida de estos cuerpos es posible, desde luego, sólo con la presencia del alma en ellos, podremos inferir por asociación que la trama es la forma que articula y da sentido o vida a un cuerpo de acciones. Con lo cual se vuelve bastante patente el lugar y la primacía que detenta la trama en el fenómeno de la tragedia. Finalmente, como hemos anticipado antes, podemos concluir en que en Poética se produce la identificación entre forma y fin no presentándose como dos cosas distintas y distinguibles a no ser, eso sí, con una finalidad expositiva.

La causa material. Aristóteles caracteriza a la causa material en Física B como "aquel constitutivo interno de que algo está hecho"40 (B 3 194b24). La discusión, heredada del Fedón, con la tradición materialista conduce a rechazar la sola explicación por la vía material, pero no a esta causa en términos absolutos. La causa material es condición, así se plantea en Fedón 99a y Aristóteles lo sostiene, para que exista la forma (y con ella también el fin) puesto que es a partir de la materia que la forma llega a ser.

Entendemos que la causa material de la tragedia está expresada a

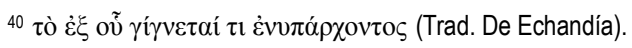


continuación de la definición, en el pasaje siguiente: "Y, dado que hacen la imitación actuando, el ordenamiento del espectáculo sería primera y necesariamente parte constitutiva de la tragedia, y además, la melopeya y la elocución, pues con estos medios hacen la imitación". ${ }^{41} \mathrm{El}$ aspecto material del fenómeno está dado por la actuación pero para que haya tal cosa se requiere de tres ítems: el orden del espectáculo, la melopeya y la elocución. El orden

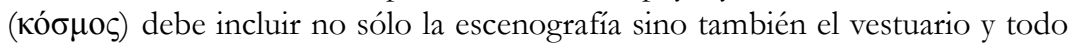
aquello que aparezca materialmente sobre el escenario. A su vez, hay dos medios "por los cuales se hace" la imitación desde un plano auditivo: 1. la melopeya ( $\mu \varepsilon \lambda o \pi$ otí $\alpha$ ), que hace a la dimensión musical de la tragedia (suponemos que se trata de las intervenciones de los coros) y 2. la elocución $(\lambda \dot{\varepsilon} \xi i \varsigma)$, que se encuentra conformada por los momentos dialogados de la obra. De este modo, consideramos que estos tres elementos son la base sobre la que se edifica materialmente la tragedia, es decir, el constitutivo del que la tragedia está hecho. De este modo concluimos el examen de la presencia de las cuatro causas en la explicación general del fenómeno de la poética pero particularmente del fenómeno de la tragedia. Extraigamos unas conclusiones sobre lo desarrollado.

\section{Consideraciones finales}

El objetivo general del trabajo apunta a defender la idea de que el examen de la técnica poética se encuadra dentro de la metodología -heredada de la astronomía y la biología- que se conoce con el nombre de "salvar las apariencias". Consideramos que dicha metodología compatibilista brinda un esquema híbrido y complejo que integra la investigación empírica con el establecimiento de las causas. Siguiendo la propuesta sugerida por Cleary aunque con algunas diferencias en cuanto al alcance- apuntamos a superar la dicotomía y la discrepancia planteada por quienes defendieron el carácter preferentemente dialéctico de los tratados científicos. Para ello desarrollamos un apartado ( $(\$ 1)$ donde pusimos el acento en mostrar que en Poética encontramos el método de "salvar las apariencias". Por un lado, mostramos la conexión que existe entre el incipit de Poética y algunos pasajes de Partes de los animales. Esta conexión nos permitió ver la unidad metodológica existente entre dichas obras y, de ese modo, volver verosímil el uso del "salvar las apariencias", claramente aludido en Partes de los animales (en conexión con Primeros analíticos I 30). Por otra parte, el otro elemento que prueba el uso del

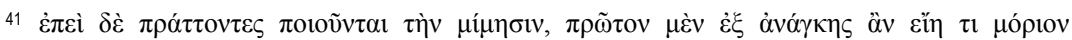

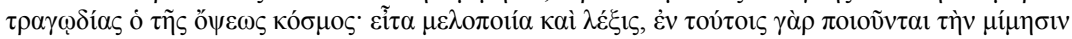
(Poética 6 1449b31-4, mi traducción). 
método de "salvar las apariencias" está en la estructura misma del tratado y en el modo en que Aristóteles expone: en $\$ 2$ y $\$ 3$ mostramos la base empírica y la presencia de las causas de la tragedia. Con más detalle, en $\int 2$ expusimos la base empírica o los phainómena que constituyen el punto de partida para la elaboración de las primeras distinciones, los criterios para distinguir entre formas de llevar a cabo la mímesis así como también para el establecimiento de las causas. Tales causas fueron expuestas en $\ 3$ : encontramos la causa eficiente en la connaturalidad de la mimesis, la causa material en el soporte visual y auditivo de las tragedias, la causa formal en la definición de la tragedia y, finalmente, la causa final en la trama. Hemos tomado un sentido amplio de phainómena para comprender de qué modo se puede constatar la existencia de una base empírica para el desarrollo de Poética para luego ver de qué modo se establecen las causas de la poética (aunque restringida a la tragedia). Si este trabajo cumplió su propósito, habremos expuesto un argumento en contra de las tesis de la discrepancia y el uso extendido de la dialéctica y a favor de una integración metodológica distinta que se enmarca bajo el título de "salvar las apariencias".

Hasta aquí nuestro desarrollo que, sin embargo, dejo un espacio para ser completado. Un tema a indagar es si estas causas continúan operando en el resto de Poética. En efecto, si bien consideramos que es así, el desarrollo de esta hipótesis es motivo de otro trabajo. Con todo, no queremos dejar de mencionarlo porque significaría un nuevo paso que completaría la "salvación de las apariencias". El establecimiento de las causas de la poética, y en particular de la tragedia, no agota el campo técnico del arte poética sino que simplemente lo circunscribe y dota de herramientas, las causas, que deberían ser útiles en desarrollos subsiguientes. Sólo si estas causas funcionan realmente pueden llegar a confirmarse como causas genuinas. Sin embargo, estos temas son materia de otra investigación.

\section{Referências}

ANGIONI, L. "As quatro causas na filosofia da natureza de Aristóteles". In: Anais de Filosofia Clássica, v.V, n.10, 2011, p.1-20.

ARISTÓTELES. As partes dos Animais. Livro I. Trad. Lucas Angioni. In: Cadernos de bistória e filosofia da ciência, Serie 3, v. 9, n.especial. 1999.

. Física I-II. Introducción, trad. y comm. de L. Angioni. Campinas: Editora Unicamp. 2009.

. Física. Trad. G. R. Echandía. Madrid: Gredos. 1995. 
Colihue, 2006.

Poética. Introd., trad., notas de Eduardo Sinnot. Buenos Aires: - Poética. Introducción, trad. y comm. Valentín García Yebra. Madrid: Gredos. Edición trilingüe (griego, latín, español), 1974.

. On Poetics. Trans. Seth Benardete \& Michael Davis. Introd. by Michael Davis. South Bend (Indiana): St. Augustine's Press, 2002.

. On the Parts of Animals I-IV. Trad y comm.: James G. Lennox. Clarendon Aristotle Series. 2001.

. Poetics. Introducción, Trad. y comm. de Joe Sachs. New Buryport: Focus Publishing. 2006.

AUBENQUE, P. Le problème de l'etre chez. Aristote. Essai sur la problematique aristotélicienne. Paris: Presses Universitaires de France. 1962.

BALME, D. Aristotle's De Partibus Animalium I and De Generatione Animalium I. Oxford: Clarendon Press. 1972.

BARBERO, S. La noción de mímesis en Aristóteles. Córdoba: El Copista. 2004.

BARNES, J. “Aristotle's Theory of Demonstration". In: BARNES, J. SCHOFIELD, M. y SORABJI, R. Articles on Aristotle. Vol. 1. Science. London: Duckworth, p.65-87, 1975.

. "Proof and the Syllogism". In: BERTI, E. Aristotle's On Science. The "Posterior Analytics". Padova: Editrice Antenore, p.17-59, 1981.

BERRÓN, M. "El rol cognitivo de los phainomena y su uso científico en los tratados de ciencia de Aristóteles”. In: Areté. Dpto. de Humanidades. PUCP. Lima: Perú, v.XXV, n.1, p.7-26, 2013.

- "Aprender a ver: el carácter activo de las facultades de la sensibilidad en Metafísica I 1, Segundos Analiticos II 19 e Investigación sobre los animales VI de

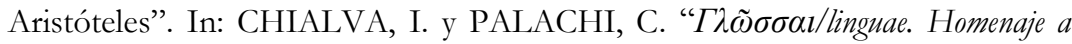
Silvia Calosso". Santa Fe: Ediciones UNL, 2015, p.141-156.

BIEDA, E. "El placer de ser feliz". In: Nova Tellus, v.23, n.1, 2005, p.99-148.

BOLTON, R. "Aristotle's Method in Natural Science: Physics I". In JUDSON, L. Aristotle's Physics: A collection of Essays. Oxford: Oxford University Press. 1991, p.1-30.

BONITZ, H. Index Aristotelicus. Berlín: Akademische Druck. 1955.

CLEARY, J. “Phainómena in Aristotle's Methodology". International Journal of Philosophical Studies. London: Routledge, p.61-97, 1994. 
CASTILLO MERLO, M. "Mimesis y máthesis: acerca de sus conexiones en la Poética de Aristóteles”. In: Diánoia, v.LXI, n.77, p.53-81, 2016.

DE MONTMOLLIN, D. La poétique d'Aristote: texte primitif et additions ultérieures. Neauchâtel: Messeiller. 1951.

DETEL, W. "Why all animals have a stomach: Demonstration and Axiomatization in Aristotle's Parts of Animals". En KULLMANN, W. y FÖLLINGER, S. Aristotelische Biologie, Intentionen, Methoden, Ergebnisse. Stuttgart: Verlag, 1997, p.63-84

DETEL, W. "Aristotle's Logic and Theory of Science”. In: GILL, M. L. y PELlEGRIN, P. A Companion to Ancient Philosophy. Malden: Blackwell. 2006, p.245-269.

DEVEREUX, D. y PELLEGRIN, P. Biologie, logique et métaphysique chez Aristote. Paris: Editions du CNRS, 1990.

ELSE, G. F. Aristotle's Poetics. The Argument. Cambridge. Harvard Unisersity Press, 1957.

ENGBERG-PEDERSEN, T. "More on Aristotelian Epagoge". In Phronesis XXIV, p.301-309, 1979.

GOTTHELF, A. "First Principles in Aristotle's Parts of Animals". In GOTTHELF, A. y LENNOX, J. Philosophical Issues in Aristotle's Biology. Cambridge: University Press. 1987, p.167-198.

. "The Elephant's Nose: Further Reflections on the axiomatic structure of biological explanation in Aristotle". In: KULLMANN, W. y FÖLLINGER, S. Aristotelische Biologie, Intentionen, Methoden, Ergebnisse. Stuttgart: Verlag, 1997, p.85-95.

HAEFLIGER, H. "La Poétique d'Aristote. Una synthèse et une intégration dans la méthodologie d'Aristote”. In: Kairos, n.9, p.97-119, 1997.

HALLIWELL, S. The Aesthetics of Mimesis. Ancient Texts and Modern Problems. Princeton/Oxford: PUP. 2002.

HUSAIN, M. Ontology and the Art of Tragedy. SUNY: University Press. 2002.

IRWIN, T. Aristotle's First Principles. Oxford: Oxford University Press. 1988.

LENNOX, J. "Aristotle On Norms of Inquiry". En HOPOS: The Journal of the International Society for the History of Philosophy of Science, v.1, n.1, p.23-46, 2011.

- Aristotle's Philosophy of Biology, Studies in the Origins of Life Science, Cambridge: University Press, 2001. 
MANSION, A. Introduction à la Physique Aristotélicienne. Louvain: Éditions de l' Intitut Supérieur du Philosophie, 1945.

MARCOS, A. "Introducción". In: ARISTÓTELES. Partes de los animales, Marcha de los animales, Movimiento de los animales. Madrid: Luarna. 2010. Trad. Rosana Bartolomé.

NUSSBAUM, M. C. The Fragility of Goodness: Luck and Ethics in Greek Tragedy and Philosophy. Cambidge: Cambridge University Press. 1986.

SOLMSEN, F. Die Entwicklung der aristotelischen Logic und Rhetorik. (Neue Philologische Untersuchungen, 4). Berlin: Weidmann. 1929.

SOLMSEN, F. "The origins and methods of Aristotle's Poetics". In: Classical Quarterly, 29, p.192-201, 1935.

SUÑOL, V. Más allá del arte: mímesis en Aristóteles. La Plata: Universidad Nacional de La Plata. 2012.

WIELAND, W. Die aristotelische Physik. Göttingen: Vandenhoeck \& Ruprecht. 1962.

E-mail: manuel.berron@gmail.com

Recebido: 06/2017

Aceito: 06/2017 